\title{
Homework characteristics as predictors of advanced math achievement and attitude among US 12th grade students
}

\author{
Thomas J. Smith ${ }^{1}$ (D) David A. Walker ${ }^{1}$ (D) Cornelius McKenna ${ }^{2}$
}

Received: 18 August 2020 / Accepted: 30 November 2021 / Published online: 16 December 2021

(c) The Author(s), under exclusive licence to Springer Nature Switzerland AG 2021

\begin{abstract}
The present study examined the 2015 Trends in international mathematics and science study "Advanced" data to examine how both the type of homework assigned and how that homework was used were related to advanced mathematics achievement and attitudes toward advanced mathematics among 12th grade students in the USA. Additionally, students' use of the internet was examined as a predictor of these outcomes. Results showed that the use of homework assignments that required students to find one or more applications of the content covered in class was a statistically significant positive predictor of both Students like learning advanced mathematics and students value advanced mathematics, while discussing homework in class was a significant, negative predictor of Students like learning advanced mathematics. Additionally, using the internet to discuss math topics with other students and to find information was significantly, positively associated with both attitudinal outcomes. Using the internet to communicate with the teacher was positively associated with Students like learning advanced mathematics scores.
\end{abstract}

Keywords Educational technology · Homework · Mathematics achievement · Mathematics attitude

\section{Introduction}

Increasing student performance in mathematics is an important goal in K-12 education, as mathematics ability is key to success and advancement in many fields. A challenge for mathematics educators is to examine the relationships among factors that may account for the performance of students so that potential improvements in instructional practices may be identified and implemented. Because of their readily

David A. Walker

dawalker@niu.edu

1 Northern Illinois University, DeKalb, IL, USA

2 Chana, USA 
malleable nature (given adequate resources and policies that permit them), two factors that are of particular interest in this realm include the use of teacher-assigned homework and the use of the internet.

\section{Homework}

Teacher-assigned homework long has been believed to affect mathematics achievement in school-aged youth. Cooper et al. (2006, p. 1) define homework as "any task assigned by schoolteachers intended for students to carry out during nonschool hours." However, the complex interactions of various factors that influence the effectiveness of homework practices has made the study of homework practices and their effect on student academic achievement difficult for researchers to address. Cooper (1989a) categorizes these factors into three broad categories: (1) characteristics of the homework assignments, (2) teacher factors, and (3) home community factors, and further concludes that homework generally has a positive effect on achievement. An early meta-analysis by Walberg et al. (1985) examining the effect of the amount of homework assigned per week on achievement concluded that this effect is large in magnitude. A meta-analysis carried out by Cooper (1989a, and summarized in Cooper 1989b) reviewed nearly 120 studies that examined the effects of homework on student achievement. These studies were divided into three groups. The first group of studies simply compared the achievement of students who were assigned homework with students who were not assigned homework. Of the 20 most recent of these studies, 14 showed positive effects of homework on achievement, with an average effect size of $d=0.21$ for the full set of 20 studies. The second set of 14 studies (Cooper 1989a, 1989b) compared the effects of assigned homework on achievement to in-class supervised study. The 14 studies yielded an average effect size of $d=0.09$. The third set of 18 studies (Cooper 1989a, b) found that the average correlation between time spent on homework and subsequent achievement across the 27 samples was $r=0.19$. An update on this meta-analysis carried out by Cooper et al. (2006), which included studies completed after 1989, found evidence for a positive influence of homework on academic achievement, whether achievement was measured by grades or by standardized tests. Among the studies in the Cooper et al. meta-analysis that involved control procedures, effect sizes ranged from $d=0.39$ to 0.97. The authors also note that the effects of homework on achievement among K-6 students are weakest, and are stronger at the 7-12 grade levels.

De Jong et al. (2000) reported that the amount of homework (defined as the number of homework tasks assigned) was the only homework variable related to achievement. However, Cooper et al. (2006) report that time spent on homework was not linearly related to achievement, and that the effectiveness of homework diminished if too much is given. A study by Trautwein et al. (2002) examined data from $N=1976$ German $7^{\text {th }}$ grade students found that the frequency of homework was positively related to math achievement, but the length of homework assignments had no significant effect on achievement. The authors also found that teacher monitoring of homework completion was not significantly related to math achievement. Fyfe 
(2016) found that teacher feedback on homework assignments resulted in higher test performance, but only for students with a low level of prior knowledge.

Besides achievement, a construct of interest when examining the effects of homework includes student attitude. As reported in Cooper et al. (2006), some studies (e.g., Covington 1998; Deslandes and Cloutier 2002; Harris et al. 1993; Jackson 2003) suggest that girls may exert greater effort on assigned homework and may possess more positive attitudes toward homework than boys. These studies, however, focus on attitudes toward homework as an outcome, rather than examining how homework is related to attitudes toward mathematics. Singh et al. (2002) —in a structural equation model they constructed examining the effects of motivation, interest, and engagement on math and science achievement-found that time spent on math homework was significantly and positively associated with attitude toward math, and a similar positive relationship was observed between time spent on science homework and attitude toward science.

Existing studies involving the effects of homework generally have examined samples of students from a broad range of abilities. Few existing studies, however, have examined the effects of homework among students who are enrolled in advanced math or science courses and, further, few studies have examined how specific characteristics of assigned homework might relate to achievement or attitudes.

\section{Student use of the internet}

Another student activity that might have some impact on student achievement and attitudes and that is closely linked to student-completed homework is student use of the internet for learning purposes. A report by the U.S. Department of Education on teachers' use of technology for school and homework assignments among children in grades 3-12 (Gray and Lewis, 2020) that was completed in response to a request by the U.S. Congress found that $77 \%$ of teachers assigned technology-based homework to their students. Among these teachers, a strong majority (86\%) reported that their students encountered little or no difficulty in these tasks due to unfamiliarity with technology. Clearly, technology is becoming an integral component of class and homework activities, an observation that became clearly evident during stay-athome conditions compelled by the COVID-19 epidemic. Cheung and Slavin (2013) summarize much of the research on technology use in education in their review of 74 such studies, where they concluded that technological innovations result in positive but small effects on student test scores. Roschelle et al. (2016) found that the use of an immediate (in the moment) online mathematics intervention afforded students with documented previous lower achievement in mathematics greater benefit; though the effect was small. However, Agasisti et al.'s (2017) analyses of PISA data across numerous countries indicated that intense use of information and communication technology (ICT) is associated, in most countries, with lower test scores. They suggest that the competency of the teacher in facilitating ICT use may be key to its success.

With regard to the effects of technology on attitudes toward mathematics, some research has been carried out that examines how technology integration is related 
to math attitudes. A meta-analysis carried out by Higgins et al. (2019) reviewed 24 studies involving 4522 participants found that, overall, technology had a significant, positive overall impact on student motivation and attitudes. The examined studies, however, focused on specific technological interventions, rather than students' use of technology use (and specifically use of the internet) for the purpose of learning mathematics. A study by White and Loong (2004) surveyed pre-adolescent students and found that a greater preference for finding mathematics material on the internet (compared to textbooks) was related to significantly lower perceived value of mathematics. White and Loong's study, however, focused on preference for the internet as a learning modality rather than the extent to which the internet actually was used.

\section{Current study}

The current study extends this research into both the effects of homework activities and the effects of internet use on student achievement as well as student attitude outcomes. Specifically, the purpose of the present study was to examine how (1) characteristics of assigned homework (type of homework, and how that homework was used) and (2) use of the internet in class activities was related to mathematics achievement and attitudes toward advanced mathematics among high school students in the US enrolled in advanced mathematics courses. To this end, a select sample of students (12th graders enrolled in advanced mathematics courses) was used, and the following research questions addressed:

RQ1 To what extent is the type of homework assigned by the advanced mathematics teacher and the teacher's use of homework related to students' advanced math achievement?

RQ2 To what extent is the type of homework assigned by the advanced mathematics teacher and the teacher's use of homework related to students' attitude toward advanced mathematics?

RQ3 To what extent is use of the internet for class activities related to students' advanced math achievement?

RQ4 To what extent is use of the internet for class activities related to students' attitude toward advanced mathematics?

\section{Method}

The present study used the Trends in International Mathematics and Science Study (TIMSS) 2015 "Advanced" data set (Martin et al. 2016). The TIMSS Advanced data contain information on 12th grade students enrolled in advanced science or mathematics courses, including data on math and science achievement, student background characteristics, school background, and teacher background. For the present 
study, we used data from the "Advanced Mathematics Population" (Martin et al., p. 3.4), which included US students in their final year of secondary school (12th grade) who had enrolled in an advanced mathematics course (i.e., Advanced Placement, International Baccalaureate, or another advanced mathematics course), as well as data from their associated advanced mathematics teacher. Students in the TIMSS sample were selected from the population of 12th grade advanced mathematics students using a two-stage stratified cluster sampling procedure where the first stage constituted a random sample of schools, and the second stage involved the selection of one or two intact classes of students (Martin et al.). School type (e.g., public vs. private) and location (e.g., metropolitan, non-metropolitan), and school performance on national exams served as stratification variables. Additionally, data from the teachers of the students advanced mathematics courses were collected. Although the vast majority of advanced math courses in the TIMSS data (98.2\%) were courses in which the teacher assigned homework to students, because this study focused on the effects of homework characteristics (type and use), we only considered those classes in which homework was assigned. The total unweighted sample size of student-teacher pairs was $N=4050$.

To address the research questions, the outcome of overall mathematics achievement as measured by the TIMSS-administered assessment was used. Reliability for the overall scores was alpha $=0.91$. Additionally, two indices of attitude toward mathematics obtained from responses to the Student Questionnaire (IEA 2014) were considered as dependent variables: the Students Like Learning Advanced Mathematics (SLM) scale and the Students Value Advanced Mathematics (SVM) scale. Scale scores were based on student responses to either 12 items (SLM scale) or 9 items (SVM scale) pertaining to the corresponding constructs; e.g., I enjoy figuring out challenging mathematics and I like studying for my mathematics class outside of school (SLM scale); and It is important to do well my mathematics class and Doing well in mathematics will help me get into the university of my choice (SVM scale). Each item was associated with four Likert response options (Agree a lot to Disagree a lot). The scale developers created composite scores from the two math attitude scales using item response theory (IRT) procedures, and these composite scores are contained in the data set. Scores from each scale have demonstrated good evidence of reliability for the US sample, with reliability alpha $=0.91$ (SLM scale) and alpha $=0.81$ (SVM scale). The type of homework assigned by the teacher as well as the teacher's use of homework was assessed by items the TIMSS Teacher Questionnaire (IEA 2014). The specific homework characteristics assessed in TIMSS are shown in Table 1.

To address RQ1 and RQ2, multiple regression analyses were carried out where indicators of the type of homework assigned were entered as predictors of TIMSS advanced mathematics achievement, and also as predictors of each of the two science attitude measures. A second set of regression analyses then was carried out that included indicators of the manner in which homework was used as predictors of the same achievement and attitude outcomes. Based on prior literature supporting a positive relationship between parental educational attainment and student attitudinal and achievement outcomes (e.g., Anderson 1980; Bakker et al. 2007; Bui 2002; Coley et al. 2007; Schlecter and Mislevy 2010; Spera 2006), and based 
Table 1 TIMSS teacher questionnaire items assessing type and use of homework assignments

\begin{tabular}{|c|c|}
\hline Item type & Item \\
\hline Type of homework & $\begin{array}{l}\text { How often do you assign the following kinds of mathematics home- } \\
\text { work to this class? } \\
\text { 1. Finding one or more applications of the content covered } \\
\text { 2. Gathering, analyzing, and reporting data } \\
\text { 3. Memorizing formulas and procedures } \\
\text { 4. Doing problem/question sets } \\
\text { 5. Working on projects } \\
\text { 6. Reading the textbook }\end{array}$ \\
\hline Teachers' use of homework & $\begin{array}{l}\text { How often do you do the following with the mathematics homework } \\
\text { assignments for this class? } \\
\text { 1. Correct assignments and give feedback to students } \\
\text { 2. Have students correct their own homework } \\
\text { 3. Discuss the homework in class } \\
\text { 4. Monitor whether or not the homework was completed } \\
\text { 5. Use the homework to contribute toward students' grades or marks }\end{array}$ \\
\hline
\end{tabular}

Response options for each item were coded as $1=$ Never or almost never, $2=$ Sometimes, and $3=$ Always or almost always

on prior research suggesting that, among high achievers, males show higher math achievement than females (Zhou et al. 2017), both gender and parental education attainment were used as control variables. For RQ3 and RQ4, seven indicators of student use of the internet as reported by the student (Table 2) were used as predictors of the two TIMSS mathematics attitude outcomes (SLM and SVM) as well as TIMSS mathematics achievement scores. For all regression analyses, supplied student-level sampling weights were used and, to account for the complex, multistage sampling design, standard errors were adjusted using jackknife replications. Each set of TIMSS science achievement scores consist of a set of five plausible values; therefore, regression analyses were carried out five times, and obtained

Table 2 TIMSS student questionnaire items assessing the use of internet in class

Do you use the Internet to do any of the following tasks for advanced mathematics schoolwork (including classroom tasks, homework, and studying outside of class)?

1. Access the textbook or other course materials

2. Access assignments posted online by my teacher

3. Collaborate with classmates on mathematics assignments or projects

4. Communicate with the teacher

5. Discuss mathematics topics with other students

6. Find information, articles, or tutorials to aid in understanding mathematics concepts

7. Find information, articles, or tutorials to aid in solving mathematics problems

Response options were coded as $0=N o$ and $1=Y e s$ 
parameter estimates averaged across these regressions. For the regression analyses, error degrees of freedom were computed as the number of PSUs (clusters) minus the number of strata (unless a stratum had a single PSU), minus the number of regressors. In the TIMSS data, some students were taught by more than one mathematics teacher. Thus the sample sizes for regressions involving teacher predictors were larger than the sample sizes for regressions involved student variables. Analyses were carried out using SPSS v.26 in combination with the IEA International Database (IDB) Analyzer (IEA 2020).

\section{Results}

Tables 3 and 4 show results for multiple regression analyses predicting Advanced Mathematics Achievement, Students Like Learning Advanced Mathematics (SLM), and Students Value Advanced Mathematics (SVM) from homework type, homework use, and the remaining regressors. For each analysis, the regression assumptions of linearity, homoscedasticity, and normality of residuals were assessed and met. Excessive multicollinearity among regressors was not evident, with no VIF values exceeding 2.0. As can be seen from these results, when controlling for student gender and parental educational background, none of the homework type and homework use indicators significantly predicted advanced mathematics achievement. However, when controlling for the other predictors, increased parental education was significantly associated with higher student advanced mathematics scores $(\beta=0.25, p<0.001)$, and females showed significantly lower advanced mathematics ability scores than males $(\beta=-0.15, p<0.001)$. For the attitudinal outcomes,

Table 3 Regression results predicting advanced mathematics ability scores from parental education, student sex, homework type, and homework use $(N=3941)$

\begin{tabular}{llrrrc}
\hline Predictor class & Predictor & \multicolumn{1}{c}{$b$} & $\mathrm{SE}(b)$ & \multicolumn{1}{c}{$\beta$} \\
\hline Demographics & Parental education & 22.52 & 2.95 & 0.25 & $7.64^{* * * *}$ \\
$\left(\Delta R^{2}=.11\right)$ & Female sex & -29.53 & 6.19 & -0.15 & $-4.77^{* * *}$ \\
Homework type & Finding & 5.20 & 6.41 & 0.03 & 0.81 \\
$\left(\Delta R^{2}<.01\right)$ & Gathering & 5.41 & 5.49 & 0.04 & 0.99 \\
& Memorizing & -8.22 & 12.22 & -0.04 & 0.67 \\
& Problem sets & 12.12 & 13.39 & 0.07 & 0.91 \\
& Projects & -14.33 & 9.52 & -0.09 & -1.50 \\
& Reading & 18.27 & 29.49 & 0.06 & 0.62 \\
Homework use & Correct homework & -7.72 & 6.94 & -0.06 & -1.11 \\
$\left(\Delta R^{2}=.01\right)$ & Students correct own homework & -11.79 & 7.86 & -0.07 & -1.50 \\
& Discuss homework & -3.12 & 8.70 & -0.02 & -0.36 \\
& Monitor homework & -5.64 & 6.18 & -0.04 & -0.91 \\
& Use homework for grades & -8.28 & 8.97 & -0.04 & -0.92 \\
\hline
\end{tabular}

$*_{p}<.05, * * p<.01, * * p<.001 . R^{2}$ for full model $=.12$. Parameter estimates have been averaged over models fitted to each of five plausible values of the outcome 


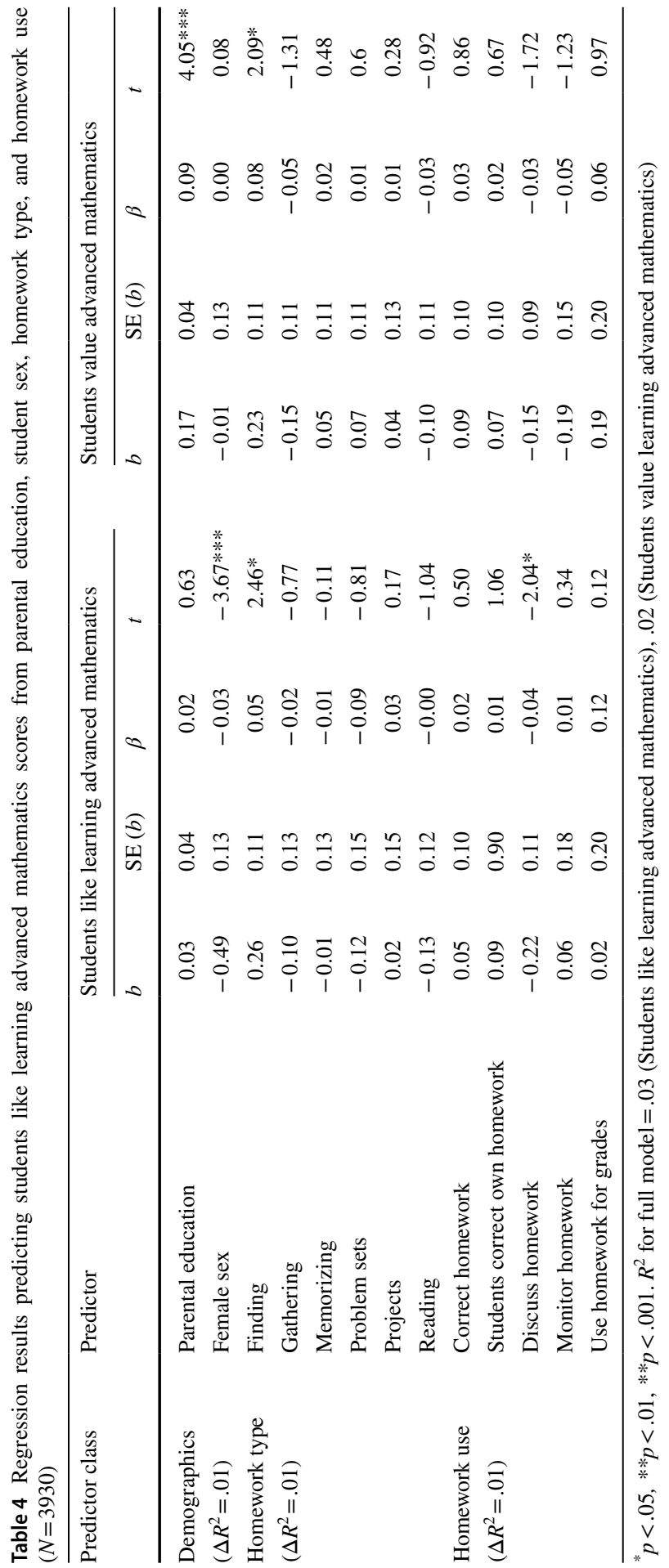


homework assignments that required students to find one or more applications of the content covered in class were a statistically significant positive predictor of both Students Like Learning Advanced Mathematics $(\beta=0.05, p=0.014)$ and Students Value Advanced Mathematics $(\beta=0.08, p=0.037)$, while discussing homework in class was a significant negative predictor of Students Like Learning Advanced Mathematics $(\beta=0.04, p=0.041)$. In each case, however, the effects were small in magnitude, accounting for $1 \%$ of the variance in each outcome.

When student use of the internet for classroom activities was considered as a predictor of advanced mathematics achievement and attitude (Tables 5 and 6), none of the indicators for internet use was significantly associated with advanced mathematics achievement. However, when the two measures of attitude toward advanced mathematics were considered as outcomes, using the internet to discuss math topics with other students was significantly, positively associated with both Students Like Learning Advanced Mathematics $(\beta=0.06, p=0.029)$ and Students Value Advanced Mathematics $(\beta=0.07, p=0.022)$. Similarly, using the internet to find information to understand math concepts also was significantly and positively associated with both attitudinal outcomes $(\beta=0.10, p=0.008$, and $\beta=0.10, p=0.016$, respectively), while using the internet to communicate with the teacher was positively associated with Students Like Learning Advanced Mathematics $(\beta=0.06, p=0.040)$.

\section{Discussion}

Although many studies have examined the effects of homework on student achievement (Dettmers et al. 2010), most have focused on how the quantity or frequency of homework is related to this outcome. Other research has focused on the frequency and amount of time spent on homework by students or the quality of homework selection as related to motivation (Trautwein and Lüdtke 2009) and homework

Table 5 Regression results predicting advanced mathematics ability scores from use of the internet for classroom activities $(N=2903)$

\begin{tabular}{llrrrr}
\hline Predictor class & Predictor & $B$ & SE $(b)$ & $\beta$ & $t$ \\
\hline Demographics & Parental education & 20.73 & 3.25 & 0.24 & $6.38^{* * *}$ \\
$\left(\Delta R^{2}=.09\right)$ & Female sex & -30.11 & 5.41 & -0.15 & $-5.56^{* * *}$ \\
Use of internet $\left(\Delta R^{2}=.01\right)$ & Access the textbook & -6.51 & 6.54 & -0.03 & -1.00 \\
& Access assignments & 9.78 & 7.51 & 0.05 & 1.30 \\
& Collaborate with classmates & -7.87 & 7.34 & -0.04 & -1.07 \\
& Communicate with teacher & -7.97 & 6.57 & -0.04 & -1.21 \\
& Discuss math topics w/other & -1.69 & 7.81 & -0.01 & -0.22 \\
& students & & & & \\
& $\begin{array}{l}\text { Find information to understand math } \\
\quad \text { concepts }\end{array}$ & 11.69 & 8.64 & 0.05 & 1.35 \\
& $\begin{array}{l}\text { Find information to solve math } \\
\text { problems }\end{array}$ & 12.65 & 10.33 & 0.06 & 1.23 \\
& problems & & & & \\
\hline
\end{tabular}

$* p<.05, * * p<.01, * * p<.001 . R^{2}$ for full model $=.10$ 


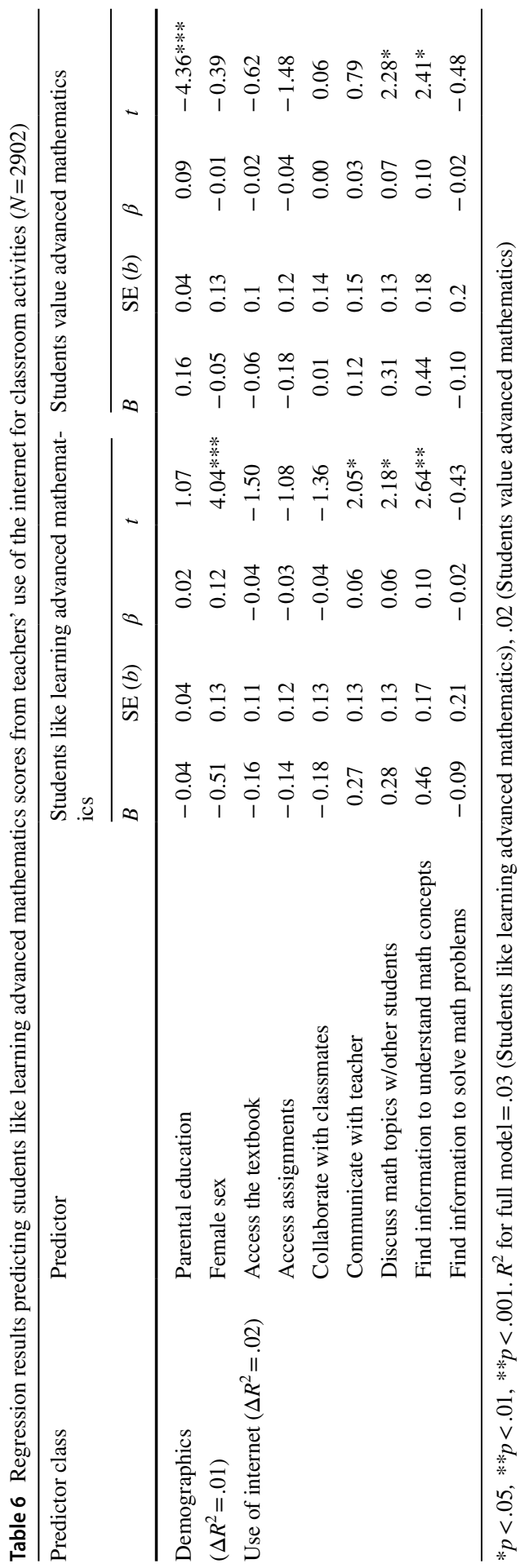


support resources (Kitsantas et al. 2011). Few studies, however, have examined the specific characteristics of homework, and few have investigated effects of such characteristics on student attitudes toward mathematics-particularly among a select group of students - those approaching the conclusion of their secondary education who are taking advanced mathematics courses. The present study found that neither homework type nor homework use significantly predicted mathematics achievement. As prior literature (e.g., De Jong et al. 2000, 2006; Cooper 1989a, b) has focused primarily on amounts of homework assigned, and there is little existing literature on the effects of homework type or homework use, these findings provide preliminary insight and suggest that differences in types of homework may matter less than the quantity of homework assigned. Similarly, use of the internet was not a significant predictor of mathematics achievement. However, when considering the extent to which students both like and value mathematics, whether students discussed math content on the internet was a positive predictor of both of these attitudinal outcomes. Conversely, discussing math content in class did not predict the extent to which students value mathematics, and was a negative predictor of the extent that students like math. This was a curious result, and suggests that the medium of communication may serve as a critical factor. Perhaps communication on the internet entails a communication style that is more intuitive and enjoyable for young students than traditional face-to-face discussion. This would be consistent with recent findings, such as Pierce (2009), who found that teens feel more comfortable talking with others in an online environment than in a face-to-face setting, and that this increased comfort with online communication was more prominent among females.

Another finding was that asking students to find information related to mathematics concepts positively predicted both liking and valuing advanced mathematics. It is likely that such class activities would entail the use of the internet and, indeed, these results were paralleled when the use of the internet to find information was specifically examined as a predictor of math attitudes. It appears then, that the internet can play a key role in shaping students attitudes toward mathematics. The implications of this are that aspects of the "digital divide" may have impact on more than student skills and achievement- they potentially may affect student attitudes, particularly among high-performing students as examined in the present study. Thus, continued efforts to ensure digital "connectedness" for all students in all schools, particularly under-privileged students or those in rural or remote areas that historically have struggled in these respects, is essential. This has become particularly relevant and important in contexts where online learning by necessity becomes to the sole educational environment, as occurred across the world during the COVID-19 pandemic. Auxier and Anderson (2020), in fact, discuss the "digital homework gap" (p. 1) whereby some school-aged children lack the digital connectivity needed to successfully complete their school work while in their homes. The authors, based on Pew Research Center data, report that $17 \%$ of teenage students reported inability to complete schoolwork at home due to lack of digital connectivity, and that this problem was more highly prevalent among Black students and students from low-income households. Clearly, continued research into the digital aspects of school workboth traditionally assigned homework and schoolwork completed during synchronous online class sessions-is critical. 


\section{Conclusions}

The current study examined characteristics of teacher-assigned homework and of student use of the internet on both mathematics achievement and attitudes toward mathematics among advanced math students. Although findings suggest no discernable impacts on student achievement, they do suggest that attitudes can in particular that online discussions might foster more positive attitudes toward mathematics. These findings have implications for how teachers might optimally design homework activities to increase the extent to which student both like and value the mathematics content that they teach and also to increase the likelihood that their students will continue their study of mathematics beyond the high school level and consider educational and career trajectories that involve these skills.

Funding Not applicable.

Data Availability Upon request from the authors.

Code availability Upon request from the authors.

\section{Declarations}

Conflict of interest Not applicable.

\section{References}

Agasisti T, Gil-Izquierdo M, and Han SW (2017) ICT use at home for school-related tasks: What is the effect on a student's achievement? Empirical evidence from OECD PISA data. https://mpra.ub.unimuenchen.de/81343/

Anderson KL (1980) Educational goals of male and female adolescents: the effects of parental characteristics and attitudes. Youth \& Society 12(2):173-187

Auxier B, Anderson M (2020) As schools close due to the coronavirus, some U.S. students face a digital 'homework gap.' https://www.pewresearch.org/fact-tank/2020/03/16/as-schools-close-due-to-thecoronavirus-some-u-s-students-face-a-digital-homework-gap/

Bakker J, Denessen E, Brus-Laeven M (2007) Socio-economic background, parental involvement and teacher perceptions of these in relation to pupil achievement. Educ Stud 33(2):177-192

Bui KVT (2002) First-generation college students at a four-year university: background characteristics, reasons for pursuing higher education, and first-year experiences. Coll Stud J 36(1):3-11

Cheung ACK, Slavin RE (2013) The effectiveness of educational technology applications for enhancing mathematics achievement in K-12 classrooms: a meta-analysis. Educ Res Rev 9:88-113

Coley RL, Bachman HJ, Votruba-Drzal E, Lohman BJ, Li-Grining CP (2007) Maternal welfare and employment experiences and adolescent well-being: do mothers' human capital characteristics matter? Child Youth Serv Rev 29(2):193-215

Cooper H (1989a) Homework. Longman, White Plains, NY

Cooper H (1989b) Synthesis of research on homework. Educ Leadersh 47(3):85-91

Cooper H, Robinson JC, Patall EA (2006) Does homework improve academic achievement? A synthesis of research, 1987-2003. Rev Educ Res 76(1):1-62

Covington MV (1998) The will to learn: a guide for motivating young people. Cambridge University, Cambridge

De Jong R, Westerhof KJ, Creemers PM (2000) Homework and student math achievement in junior high schools. Educ Res Eval 6(2):130-157 
Deslandes R, Cloutier R (2002) Adolescents' perception of parental involvement in schooling. Sch Psychol Int 23(2):220-232

Dettmers S, Trautwein U, Lüdtke O (2010) Homework works if homework quality is high: using multilevel modeling to predict the development of achievement in mathematics. J Educ Psychol 102(2):467-482

Fyfe ER (2016) Providing feedback on computer-based algebra homework in middle-school classrooms. Comput Hum Behav 63:568-574

Gray L, Lewis L (2020) Teachers' use of technology for school and homework assignments: 2018-19 (NCES 2020-048). U.S. Department of Education, National Center for Education Statistics, Washington, DC. https://nces.ed.gov/pubsearch/pubsinfo.asp?pubid=2020048.

Harris S, Nixon J, Rudduck J (1993) School work, homework and gender. Gend Educ 5(1):3-14

Higgins K, Huscroft-D’Angelo J, Crawford L (2019) Effects of technology in mathematics on achievement, motivation, and attitude: a meta-analysis. Journal of Educational and Computing Research 57(2):283-319

IEA (2014) Trends in International Mathematics and Science Study: teacher questionnaire advanced mathematics. https://timssandpirls.bc.edu/timss2015/advanced-questionnaires

IEA (2020) IEA international database analyzer (IDB) analyzer. https://www.iea.nl/data-tools/tools

Jackson C (2003) Motives for "laddishness" at school: fear of failure and fear of the "feminine." Br Edu Res J 29(4):583-598

Kitsantas A, Cheema J, Ware HW (2011) Mathematics achievement: the role of homework and self-efficacy beliefs. J Adv Acad 22(2):310-339

Martin MO, Mullis IVS, Hooper M (2016) Methods and procedures in TIMSS Advanced 2015. http:// timss.bc.edu/publications/timss/2015-a-methods.html

Pierce T (2009) Social anxiety and technology: face-to-face communication versus technological communication among teens. Comput Hum Behav 25(6):1367-1372

Roschelle J, Feng M, Murphy RF, Mason CA (2016) Online mathematics homework increases student achievement. AERA Open 2(4):1-12

Schlechter M, Milevsky A (2010) Parental level of education: associations with psychological well-being, academic achievement and reasons for pursuing higher education in adolescence. Educ Psychol 30(1):1-10

Singh K, Granville M, Dika S (2002) Mathematics and science achievement: effects of motivation, interest, and academic engagement. J Educ Res 95:323-332

Spera C (2006) Adolescents' perceptions of parental goals, practices, and styles in relation to their motivation and achievement. J Early Adolesc 26(4):456-490

Trautwein U, Lüdtke O (2009) Predicting homework motivation and homework effort in six school subjects: the role of person and family characteristics, classroom factors, and school track. Learn Instr 19(3):243-258

Trautwein U, Köller O, Schmitz B, Baumert J (2002) Do homework assignments enhance achievement? A multilevel analysis in 7th-grade mathematics. Contemp Educ Psychol 27(1):26-50

Walberg HJ, Paschal RA, Weinstein T (1985) Homework's powerful effects on learning. Educ Leadersh 42(7):76-79

White B, Loong EYK (2004) Student perceptions of internet use in the mathematics classroom. Proceedings of the Australian Computers in Education Conference. ACEC. http://hdl.handle.net/10536/ DRO/DU:30025748

Zhou Y, Fan X, Wei X, Tai RH (2017) Gender gap among high achievers in math and implications for STEM pipeline. Asia-Pacific Res 26:259-269 